1. Köhler, H. Trans. Far. Soc. 32, 1152-1161 (1936).

2. Shulman, M. L., Jacobson, M. C., Charlson, R. J., Synovec, R. E.

\& Young, T. E. Geophys. Res. Lett. 23, 277-280 (1996).

4. Korhonen, P., Kulmala, M. \& Vesala, T. Atmos. Env. 30, 1773-1785 (1996).

5. Laaksonen, A., Korhonen, P., Kulmala, M. \& Charlson, R. J. J. Atmos. Sci. (submitted).

6. Pruppacher, H. R. \& Klett, J. D. Microphysics of Clouds and Precipitation 142 (Reidel, Dordrecht, 1980).

7. Hänel G. Adv. Geophys. 19, 73-188 (1976).

8. CRC Handbook of Chemistry and Physics 74th edn (eds Lide, D. R. \& Frederikse H. P. R.) 4-49 (CRC, Boca Raton, 1993). 9. Del Monte, M. \& Rossi, P. Atmos. Environ. 31, 1637-1646 (1997). 10. Brimblecombe, P. \& Clegg, S. L. Atmos. Env. 24A, 1945-1955 (1990).

\section{A new west African}

\section{chimpanzee subspecies?}

We have sequenced a portion of the mitochondrial DNA control region from the hairs of Nigerian chimpanzees living on both sides of the Niger River, which is proposed as a biogeographic boundary. Our data suggest that a previously unrecognized type of chimpanzee may be present in Nigeria and adjacent parts of Cameroon, and that the zoogeographic barriers separating chimpanzees are different from those previously proposed.

Three subspecies of the common chimpanzee are generally recognized: west African Pan troglodytes verus, central African P. $t$. troglodytes and east African P. t. schweinfurthii with the lower Niger River separating P. t. verus and P. t. troglodytes ${ }^{1}$. Mitochondrial DNA (mtDNA) sequences ${ }^{2}$ are consistent with this view although they tentatively elevate $P$. $t$. verus to the status of a full species (Pan verus). Given the 1,700-km gap in the sampling distribution between western and central African chimpanzees in ref. 2 (Fig. 1a), the long-term genetic isolation of $P$. $t$. verus populations has been questioned ${ }^{3}$.

To investigate geographically intermediate populations and the phylogeographic 'break' between subspecies believed to occur at the lower Niger, we studied a $600-\mathrm{km}$ span
3. Kulmala, M. et al. J. Geophys. Res. 98, 22949-22958 (1993).

of Nigeria (Fig. 1b), collecting 12 chimpanzee hair samples from nests, captive individuals and skins. From those samples, we sequenced 414 base pairs of the mtDNA control region (D-loop). A combined data set of 87 individuals, including sequences obtained from GenBank ${ }^{4}$, was analysed using the neighbour-joining method and maximum parsimony and likelihood searches ${ }^{5}$, to give a $50 \%$ majority-rule consensus tree based on 10,400 equally parsimonious trees (Fig. 2).

All the Nigerian chimpanzees, from both sides of the Niger, form a single, distinct cluster, most closely allied with the $P$. $t$. verus clade. Two genetically distinct chimpanzee forms are inferred in west Africa: one group restricted to far-west Africa (Senegal to Ghana) and the other from Nigeria and probably adjacent parts of Cameroon.

In the sequenced mtDNA region, the two west African lineages differ at least as much as do the eastern and central forms. These differences might be the result of two alternative taxonomies. Either Nigerian chimpanzees are classified within $P$. t. verus, and $P$. t. troglodytes and P. t. schweinfurthii are collapsed into another subspecies, or Nigerian chimpanzees are a separate subspecies, along with the other three named subspecies. If a fourth subspecies is eventually recognized, the name vellerosus seems to be available ${ }^{6}$. These proposals need to be confirmed by more extensive sampling, sequencing of several independent nuclear loci and morphological data.

The Niger River has been proposed to separate western and central chimpanzees. Our findings suggest, however, that the Niger has not been a substantial boundary to gene exchange. Instead, chimpanzees in eastern Nigeria and those south of the Sanaga River in Cameroon, separated by only $200 \mathrm{~km}$, have sufficiently divergent sequences to place them in the western and central chimpanzee clades, respectively. We therefore suggest that a phylogeographic discontinuity between western and central chimpanzees is located somewhere between the Cameroon Highlands in Nigeria and the banks of the Sanaga River in

Figure 1a, Localities from which chimpanzee mtDNA was sampled by Morin et al. ${ }^{2}$ b, Sources of new samples from Nigeria. 1, Ondo State forests (confiscated skins); 2, Donga Valley (captive); 3, Mambilla Plateau (nest hairs); 4, Gashaka-Gumti National Park (nest hairs).

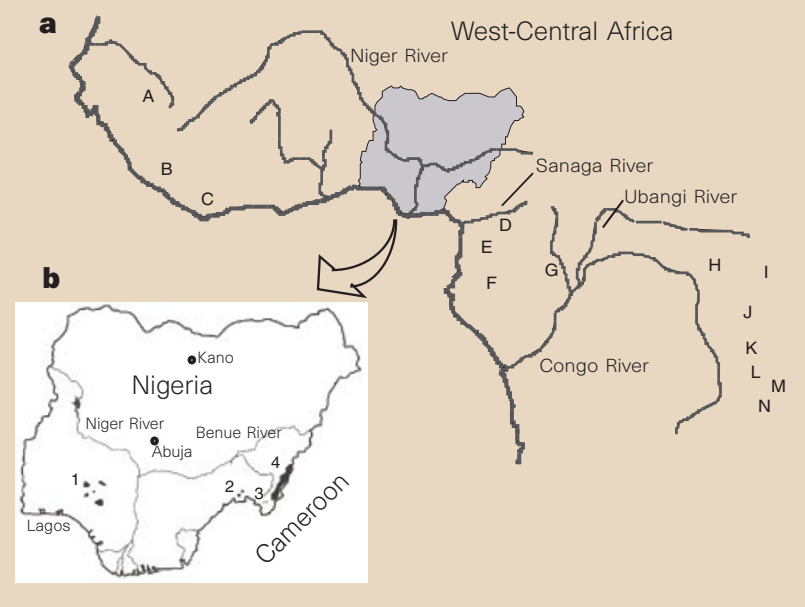

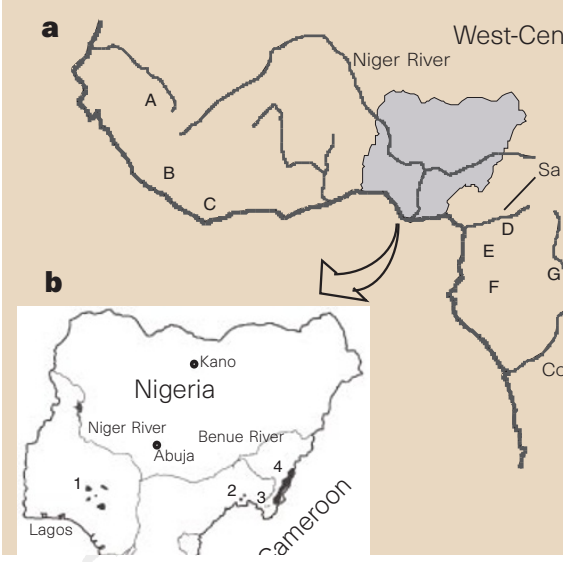

Figure 2 Phylogeny derived using a maximum parsimony analysis of chimpanzee mtDNA D-loop sequences. Triangles at the tips of branches represent a monophyletic cluster of individuals. Letters or numbers after names refer to localities in Fig. 1.

Cameroon. Distribution data for several other primates suggest the Sanaga River is an important boundary for many taxa ${ }^{7}$. A major genetic discontinuity has also been noted for gorillas from western and eastern Africa ${ }^{8,9}$.

West African chimpanzees are the most threatened with extinction ${ }^{10}$. Chimpanzees in Nigeria and western Cameroon are especially endangered, as a result of hunting and habitat destruction. These animals now appear to constitute a genetically distinct evolutionary unit which has been neglected in conservation planning and should be given immediate attention.

\section{Katherine Gonder}

\section{John F. Oates}

Hunter College and the Graduate School of the

City University of New York,

Department of Anthropology, Hunter College,

695 Park Avenue, New York, NewYork 10021, USA

Todd R. Disotell

Department of Anthropology, New York University, 25 Waverly Place, New York, New York 10003, USA

\section{Michael R. J. Forstner}

\section{Juan Carlos Morales, Don J. Melnick}

Center for Environmental Research and Conservation, and ${ }^{\star}$ Departments of Anthropology and Biological Sciences,

Columbia University, 1200 Amsterdam Avenue, New York, New York 10027, USA

1. Hill, W. C. O. in The Chimpanzee Vol. 1(ed. Bourne, G. H.) 22-49 (Karger, Basel, 1969)

2. Morin, P. A. et al. Science 265, 1193-1201 (1994).

3. Jolly, C., Oates J. F. \& Disotell, T. R. Science 268, 185-186 (1995).

4. Benson, D., Bojuski, M., Lipman, D. J. \& Ostell, J. J. Nucleic Acids Res. 24, 1-5 (1996).

5. Swofford, D. L., Olsen, G. J., Waddell, P. J. \& Hillis, D. M. in Molecular Systematics 2nd edn (eds Hillis, D. M., Moritz, C. \& Mable, B. K.) 407-514 (Sinauer, Sunderland, MA, 1996).

6. Gray, J. E. Proc. Zool. Soc. Lond. 180-181 (1862).

7. Grubb, P. in Vertebrates in the Tropics (eds Peters, G. \& Hutterer, R.) 187-214 (Museum Alexander Koenig, Bonn, 1990).

8. Ruvolo, M. et al. Proc. Natl Acad. Sci. USA 91, 8900-8904 (1994).

9. Garner, K. J. \& Ryder, O. A. Mol. Phylogenet. Evol. 6, 39-48 (1996).

10. Teleki, G. in Understanding Chimpanzees (eds Heltne, P. G. \& Marquardt, L. A.) 312-353 (Harvard Univ. Press, Cambridge, MA, 1989). 